\title{
O PROGRAMA FUNDESCOLA: CONCEPÇÕES, OBJETIVOS, COMPONENTES E ABRANGENNCIA - A PERSPECTIVA DE MELHORIA DA GESTÃO DO SISTEMA E DAS ESCOLAS PÚBLICAS
}

\author{
JoÃo Ferreira de Oliveira* \\ Marília FonseCA ${ }^{* *}$ \\ Mirza Seabra Toschi ${ }^{* * *}$
}

\begin{abstract}
RESUMO: O presente texto apresenta os impactos do Programa FUNDESCola (Fundo de Desenvolvimento da Escola), voltado para a gestão das escolas fundamentais das regiōes Norte, Nordeste e Centro-Oeste. A investigação analisa o impacto dessas experiências na gestão e na organização do trabalho escolar. Mostra como o FUNDESCOLA materializou-se no Estado de Goiás, imprimindo uma visão gerencial "estratégica", centrada na racionalização de gastos e na eficiência operacional. Mostra que, dentro da esfera governamental pública, convivem duas concepçôes antagônicas de gestão educacional. Uma de caráter gerencial (PDE) e outra que sinaliza a aspiração da comunidade educativa por uma escola mais autônoma e de qualidade (PPP). Mostra que alguns estados tendem a privilegiar o PDE, em detrimento do projeto político-pedagógico da escola (PPP).

Palavras-chave: Gestão de escolas fundamentais. Políticas públicas e financiamento da educação. Política educacional. Planejamento escolar.
\end{abstract}

* Professor da Faculdade de Educação da Universidade Federal de Goiás (UfG). E-mail: joaofo@terra.com.br

** Pesquisadora associada da Faculdade de Educação da Universidade de Brasília (UNB) e professora-visitante da Faculdade de Educação da Universidade Federal de Uberlândia (UFU). E-mail:marilia@unb.br

*** Professora da Universidade Estadual de Goiás (UEG).E-mail: mirzas@brturbo.com

Educ. Soc., Campinas, vol. 26, n. 90, p. 127-147, Jan./Abr. 2005

Disponível em <http://www.cedes.unicamp.br> 
O programa Fundescola: concepções, objetivos, componentes e abrangência...

THE FUNDSCHOOL PROGRAM: CONCEPTIONS, OBJECTIVES, COMPONENTS AND RANGE - THE PERSPECTIVE OF ADMINISTRATION SYSTEM IMPROVEMENT AND OF THE PRIVATE SCHOOLS

ABSTRACT: This text presents the impacts of Fundschool "Fundescola" Program (Fund for School Development). This Program applies to administration of elementary schools in the North, Northeast and Central East regions of Brazil. This investigation analyses the impact of these experiences on administration and organization of the school work. It shows how the Fundschool Program happened in Goiás (Brazil). It was implemented in an administrative "strategic" view, centered on rationalization of expenses and operational efficiency. This investigation also shows that within public governmental sphere, there are two opposite conceptions of educational administration. The first one has "managerial characteristics" (School Development Plan), the other which signals the aspiration of educational community for a more autonomous and high standards school (Politic-Pedagogical Project). Some schools tend to give privilege to School Development Plan in opposition to Politic-Pedagogical Project.

Key words: Administration of elementary school. Public politics and financing in education. Educational policy. Scholarship planning.

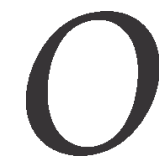

Fundo de Fortalecimento da Escola (Fundescola) é um programa oriundo de um acordo de financiamento entre o Banco Mundial (BM) ${ }^{1}$ e o MEC, desenvolvido em parceria com as secretarias estaduais e municipais de Educação dos estados envolvidos. A missão do programa é o desenvolvimento da gestão escolar, com vistas à melhoria da qualidade das escolas do ensino fundamental e à permanência das crianças nas escolas públicas, nas regiões Norte, Nordeste e Centro-Oeste.

Para realizar tais propósitos, segundo o Manual de Operação e Implementação do Projeto (Brasil/MEC/FundesCOLA, 2002), o programa privilegia o desenvolvimento de ações que funcionem em sinergia com outras iniciativas e programas governamentais de educação, entre eles o Programa Dinheiro Direto na Escola (PDDE); o Sistema Nacional de Avaliação da Educação Básica (SAEB); o Fundo de Manutenção e Desenvolvimento do Ensino Fundamental e de Valorização do Magistério (FUNDEF). 
O programa propõe-se ainda a implementar ações de fortalecimento da escola por meio de convênios com os municípios, mediante adesão desses municípios. Para tanto, estados, municípios e escolas devem adotar a metodologia de planejamento estratégico, consubstanciada no modelo do PDE, que leve à racionalização, eficácia e eficiência da gestão e do trabalho escolar.

Cada acordo dura em média seis anos, sendo que o "Acordo de Participação" inicial, ou seja, do FUNDESCOLA I, teve início em $1997 .{ }^{2}$

A autonomia escolar realiza-se mediante uma estratégia que se diz descentralizadora, por meio de um fundo repassado à escola, com vistas a estimular o quadro administrativo a tomar decisões que afetem materialmente a escola e a responsabilizar-se pelos resultados de suas decisões. Para tanto, os principais depositários do programa são os tomadores de decisões educacionais, como diretores, professores e outros especialistas.

É preciso considerar que as propostas de descentralização e autonomia estabelecidas pelo FUNDESCOLA se respaldam na própria orientação da legislação educacional brasileira. A Lei de Diretrizes e Bases da Educação Nacional - LDB (Lei n. 9.394/96) propõe a organização do espaço físico e do trabalho pedagógico, a participação dos atores escolares e a integração entre escola e comunidade. O Plano Nacional de Educação - PNE (Lei n. 10.172/01) propõe a autonomia escolar, mediante a descentralização do financiamento da educação e da administração e do controle dos recursos financeiros. A adoção de fundos de natureza contábil permite o controle local mais eficaz e a destinação de recursos para atividades fins.

Porém, para o exercício da autonomia, o Plano estabelece que cada sistema de ensino deverá implantar a chamada gestão democráti$c a$, ancorada na co-responsabilidade entre os diferentes níveis administrativos (União, estados e municípios), demandando um regime de colaboração entre fóruns nacionais e locais de planejamento, conselhos de educação em seus diferentes níveis, além da participação da comunidade educacional e da família em decisões afetas à escola.

Para a consecução da gestão democrática, a LDB (em seu inciso I, art. 13) estabelece que é tarefa do estabelecimento de ensino elaborar e executar sua proposta pedagógica ou projeto político-pedagógico (PPP), cabendo a participação dos docentes no processo. O PNE 
O programa Fundescola: concepções, objetivos, componentes e abrangência...

considera o PPP como elemento essencial da gestão e autonomia escolares, ressaltando a participação dos profissionais da educação e da comunidade escolar em conselhos escolares ou equivalentes. É nesta perspectiva que se delineia um novo sentido de gestão escolar, a gestão democrática, entendida como ação que prevê a descentralização pedagógica e administrativa como um meio para alcançar a participação mais decisória dos protagonistas escolares.

Os documentos que expressam a concepção do FUNDESCOLA (Marra et al., 1999; Brasil/MEC/FUndesCOLA, 2002, 2003) mostram que a gestão educacional incorpora um sentido peculiar, que não alcança o caráter democrático outorgado pelos textos legais. A visão estratégica do programa incide sobre a organização racional do sistema, a partir da aquisição, pelos agentes escolares, de "atributos gerenciais", "ferramentas de gestão" e "treinamento". Entre os pontos importantes presentes no FUNDESCOLA, são citados:

a) a sinalização de se trabalhar com estratégias orientadas na escola, com foco na sala de aula e na aprendizagem;

b) o desenvolvimento de produtos e estratégias para a superação dos principais problemas que afetam o sistema educacional;

c) a preocupação com o alinhamento estratégico de políticas, programas, projetos e ações das partes interessadas;

d) o adensamento das intervençôes em áreas prioritárias $\left(\mathrm{ZAP}^{3}\right)$, potencializando os resultados;

e) a montagem de estruturas de suporte local para a implementação das estratégias.

É preciso ter em conta que qualquer acordo firmado com o BM traz condicionalidades, definidas a priori e que fundamentam a negociação com autoridades nacionais. Entre elas, o chamado Appraisal Report, ${ }^{4}$ onde se estabelecem prazos, montante de recursos, metodologias e rotinas, além da distribuição de recursos por ações prioritárias. Não obstante o Banco acenar com a possibilidade de negociação, a fixação de condicionalidades é prerrogativa do emprestador. A história dos acordos antecedentes Brasil/BM mostra uma tendência, se não à aceitação quase irrestrita das condicionalidades, pelo menos ao 
seu compartilhamento entre o governo brasileiro e o Banco no que se refere aos conceitos e às metodologias mais nucleares.

Um dos documentos que fixam as orientaçôes gerais para a implementação da terceira fase do Projeto FUNDESCOLA ${ }^{5}$ expressa a necessidade de que os programas financiados com recursos do Fundo Nacional de Desenvolvimento da Educação (FNDE/BIRD) devem seguir rotinas, instrumentos e orientações para execução, acompanhamento e avaliação das ações programadas pelo projeto, definidas em conjunto com o BM. Entre as orientações incluem-se as cláusulas como o acordo de empréstimo, as normas fixadas para aquisições e editais nacionais e internacionais com os empréstimos, para contratação de consultores, sistemática para emissão e apresentação de certificados de despesa, manuais de orientação para execução do Dinheiro Direto na Escola e para a elaboração do Plano de Desenvolvimento da Escola $(\mathrm{PDE})$, além de uma série de outros manuais e instruçóes para levantamento da situação escolar.

\section{O FUNDESCOLA, sua abrangência, missão e objetivos}

O programa FUNDESCOLA constitui-se de um conjunto de três projetos I, II e III. Ao passo que o FUNDESCOLA I financiou o início das atividades do programa em dez microrregiōes da Regiāo Norte e do Centro-Oeste, o FUndescola II dá continuidade às atividades do primeiro e incorpora nove microrregióes das capitais dos estados do Nordeste e oito microrregióes adicionais do Norte e do Centro-Oeste. Ao todo, o FUNDESCOLA II planejou atingir prioritariamente 4,7 milhões de crianças matriculadas em 13.500 escolas de 247 municípios localizados em 27 microrregióes, o que corresponde a 29\% dos alunos da escola fundamental pública (World Bank, 1999, p. 9). ${ }^{6}$

Foram definidas, como alvos prioritários para a destinação de recursos, as regiōes mais pobres do Brasil, Norte, Nordeste e CentroOeste, e, dentro destas, as microrregióes mais populosas, definidas pelo Instituto Brasileiro de Geografia e Estatística (IBGE), e as escolas onde se concentra a maioria dos pobres.

O FUNDESCOLA define metas de melhoria para os indicadores de desempenho educacional do Sistema Nacional de Avaliação da Educação Básica (SAEB), nas áreas atingidas pelo programa, até o ano de 2007 (World Bank, 1999, p. 8 e 70): 
O programa Fundescola: concepções, objetivos, componentes e abrangência...

a) aumentar o número de graduados no ensino primário em $70 \% ;^{7}$

b) aumentar as taxas de aprovação do ensino fundamental em $15 \%$;

c) aumentar a proporção de estudantes de quarta série com padrōes aceitáveis de aprendizagem, de 28\% (N); 43\% (NE); $54,9 \%$ (CO), em 1997, para 50\% em 2007;

d) aumentar a proporção de estudantes de oitava série com padrôes aceitáveis de aprendizagem de 43,6\% (N); 43,8\% (NE) e 54,9\% (CO), em 1997, para 60\% em 2007;

e) aumentar as taxas médias de aprovação na escola primária (sic) de 64,2\%(N); 64,7\% (NE) e 71,5\% (CO), em 1997, para $85 \%$ em 2003.

O Fundescola integra os seguintes "produtos": Padrões Mínimos de Funcionamento das Escolas; Levantamento da Situação Escolar; Microplanejamento; Sistema de Apoio à Decisão Educacional; Programa Dinheiro Direto na Escola; Projeto de Adequação dos Prédios Escolares; Espaço Educativo; Mobiliário e Equipamento Escolar; Atendimento Rural; Escola Ativa; ProformaÇÃo; Programa de Gestão da Aprendizagem Escolar; Projeto de Melhoria da Escola; Informatização; Plano de Carreira; Desenvolvimento Institucional PRASEM; Programa de Apoio aos Secretários Municipais de Educação; Justiça na Educação; Encontro dos Conselheiros do Fundef; Comunicação; Plano de Desenvolvimento da Escola (PDE)

O PDE é entendido como o carro-chefe do FUNDESCOLA, uma vez que assinala uma ênfase na "escola com foco no aluno". ${ }^{9}$ Nesse processo, a escola é tida como responsável pela melhoria da qualidade de ensino e o projeto visa a modernizar a gestão e fortalecer a autonomia da escola, segundo um processo de planejamento estratégico coordenado pela liderança da escola e elaborado de maneira participativa. A busca do apoio público ao desenvolvimento centrado na escola é um ingrediente essencial para assegurar o clima político e os recursos para a sustentação e a expansão do processo de desenvolvimento da educação. Uma das gestoras entrevistadas, da Secretaria de Estado da Educação em Goiás, assevera que "o PDE não é projeto de captação de recursos! É proposta filosófica e metodológica de planejamento estratégico da escola”. 
Como o programa firma as bases do seu conceito de qualidade no funcionamento do sistema, um dos componentes principais é o PMFF ou Padróes Mínimos de Funcionamento. De acordo com o Manual de Operação e Implementação do Projeto (Brasil/Mec/fundescola, 2002), trata-se de um modelo para operacionalizar o conceito de escola funcional, centrado na definição de um padrão de referência predeterminado de insumos necessários para melhorar o equilíbrio educacional com relação aos pré-requisitos educacionais. Constitui, portanto, o ponto de partida para a melhoria da qualidade da educação.

Com o objetivo de melhorar a prática dos profissionais da educação, segundo o documento citado (idem, ibid., p. 31), uma vez que os alunos dependem de habilidades, competências, conhecimentos e efetividade dos professores, para elevar o desempenho escolar, o FUNDESCOLA III implementa o Programa de Gestão da Aprendizagem Escolar (GESTAR), integrando vários modelos pedagógicos inovadores, desenvolvidos e testados nas duas primeiras fases do FUNDESCOLA. Para tanto, são produzidos manuais e guias que descrevem os processos de implementação e operacionalização dos modelos, com os seguintes pontos comuns:

a) orientação para o currículo do aluno, visando a elevar o desempenho escolar;

b) adoção dos pressupostos teóricos dos Parâmetros Curriculares Nacionais (PCNS);

c) incorporação das melhores práticas de sala de aula, que são implementadas por meio da formação continuada de vários atores;

d) incentivo à formação profissional dos professores, coordenadores pedagógicos e diretores, com foco na organização da escola e, diretamente, na melhoria do desempenho escolar;

e) inclusão de práticas inovadoras e formas efetivas de engajar os alunos numa aprendizagem significativa.

Um dos objetivos centrais do GESTAR é a formação continuada em serviço da equipe de professores. No atendimento da $5^{\mathrm{a}}$ à $8^{\mathrm{a}}$ séries, a formação continuada em serviço materializa-se por intermédio de "cadernos de teoria e prática, bem como em eventos de formação, 
O programa Fundescola: concepções, objetivos, componentes e abrangência...

organizados por meio de seminários, grupos de estudo e oficinas de trabalho, que se destinam à formação de professores e de formadores" (idem, ibid., p. 33). Faz parte do GESTAR uma série de outras ações de avaliação, apoio pedagógico, diagnóstico, monitoramento, além do repasse de instrumentos e sistemas informatizados às secretarias de Educação que permitam a tomada de decisão.

Implantação, expansão e universalização do PDE em Goiás

Em Goiás, o FUNDESCOLA e, particularmente, o PDE, teve início em 1998, sendo incorporado pelo Planejamento Estratégico da Secretaria Estadual de Educação (SEE) e pelo Plano de Gestão do Sistema de Ensino. Desde então, a SEE vem incluindo nos Planos Plurianuais (PPA) objetivos que induzem a maior intervenção nas escolas, especialmente por meio do PDE.

De acordo com dados da SEE, o valor do financiamento do FUNDESCOLA, por escola, tem por base o número de alunos no ensino fundamental, indicado no Censo Escolar do ano anterior à assinatura do convênio (Estado de Goiás/SEE/COEP, 2001). Os recursos, conforme mostra a Tabela 1 , podem chegar a $\mathrm{R} \$ 15.000,00$ por escola/ano.

\section{Tabela 1}

Financiamento das ações do PDE/PME - Convênio FUNDESCOLA

\begin{tabular}{|l|c|}
\hline Tamanho da escola por $\mathbf{n}^{\mathbf{0}}$ de aluno & Faixa de financiamento \\
\hline De 100 a 199 alunos & $4.400,00$ \\
\hline De 200 a 500 alunos & $6.200,00$ \\
\hline De 501 a 1.000 alunos & $10.000,00$ \\
\hline De 1.001 a 1.500 alunos & $12.000,00$ \\
\hline Acima de 1.500 alunos & $15.000,00$ \\
\hline
\end{tabular}

Fonte: Estado de Goiás, SEE, 2001.

$\mathrm{Na}$ fase de implantação do PDE, 100\% dos recursos advêm do FUNDESCOLA, sendo $60 \%$ para custeio e $40 \%$ para capital. Na fase de expansão, 70\% dos recursos advêm do FUNDESCOLA e 30\% das secretari- 
as (estadual ou municipais). $\mathrm{Na}$ fase de consolidação $I$, os recursos são divididos igualmente e, nas fases de consolidação II e III, o FUNDESCOLA entra com 30\% e as secretarias com 70\%. Nessa fase, 30\% do financiamento é para capital e $70 \%$ para custeio. ${ }^{10}$ Em Goiás, com o processo de universalização do PDE na rede estadual, o estado assumiu 100\% dos recursos em cada escola.

O PDE, como principal "produto" do FUNDESCOLA, busca o aperfeiçoamento da gestão da escola pública e a melhoria da qualidade de ensino, mediante a elaboração do Plano. Ao prepará-lo, a escola aponta seus objetivos, estratégias, metas e planos de ação a serem alcançados. Com o PDE, a escola faz um diagnóstico de sua situação, define seus valores e sua missão. Recebem apoio técnico para elaborar o PDE as escolas que tenham a partir de 100 alunos, organizem unidades executoras (Conselho Escolar), disponham de condições mínimas de funcionamento e possuam liderança forte.

A primeira fase - FUNDESCOLA I - iniciou-se com a adesão dos governos estaduais e municipais que formam Zonas de Atendimento Prioritário (ZAP) por meio de acordo de participação que fixa compromissos e responsabilidades para o governo federal, os estados e os municípios. Cada ZAP conta com um fórum que orienta o planejamento, definindo ações prioritárias de acordo com as necessidades de cada microrregião, conforme recursos locais. Participam do fórum secretários estaduais de Educação, prefeitos dos municípios participantes, delegados do MEC nos estados e o presidente estadual da União dos Dirigentes Municipais de Educação (UnDime).

O repasse de recursos para as ações segue as rotinas de programação estabelecidas pelo Fundo Nacional de Desenvolvimento da Educação (FNDE). No caso de programas que transferem dinheiro diretamente para as escolas, como o PDDE, são celebrados convênios com estados e municípios, de acordo com a dependência administrativa da escola.

O acompanhamento dos projetos nos estados é realizado pela Coordenação Estadual Executiva (COEP) e por Grupos de Desenvolvimento Escolar (GDE), responsáveis pelo treinamento do pessoal das escolas, ambos sediados nas secretarias de Educação.

No âmbito escolar, a gestão dos projetos é realizada por uma "equipe de sistematização do PDE", composta pelo diretor da escola, 
O programa Fundescola: concepções, objetivos, componentes e abrangência...

coordenador do PDE e coordenador de objetivos estratégicos. Cabe-lhes implementar o PDE e direcionar os fundos transferidos pelo FUNDESCOLA para as diferentes ações, organizadas na forma de "gerências" e que passam a compor o chamado Projeto de Melhoria da Escola (PME).

Para promover uma gestão de pessoal mais eficaz, o projeto aproveita a experiência do treinamento e da capacitação de secretários municipais e estaduais de Educação (PRASEM), realizados no âmbito do Projeto de Educação Básica para o Nordeste, especialmente no que se refere a técnicas eficazes de gestão e à responsabilidade na prestação de contas do projeto.

Com o fim de garantir a eficiência das COEPs e dos GDEs na execução das açôes, o projeto conta também com o apoio institucional do Programa das Nações Unidas para o Desenvolvimento (PNUD), envolvendo a contratação de consultores nas áreas de planejamento estratégico. No que diz respeito à capacidade institucional, estadual e municipal, para o desenvolvimento do projeto, o PNUD apóia o Sistema Integrado de Informações Gerenciais (SIIG) e sistemas de microplanejamento em mais de 247 secretarias municipais de Educação.

Em Goiás, definiu-se que o PDE deveria alcançar todas as escolas com mais de 100 alunos. Inicialmente, foi implantado na Zona de Atendimento Prioritário I (ZAP I), ou seja, em Goiânia e seu entorno (Grande Goiânia) e, posteriormente, na ZAP II. ${ }^{11}$ Essas zonas buscam agregar as microrregiōes com municípios mais populosos, conforme definição do Instituto Brasileiro de Geografia e Estatística (IBGE). De um modo geral, a seleção dos municípios e a indicação das escolas é realizada pela direção central do programa, em conjunto com o estado.

$\mathrm{Na}$ fase inicial, o PDE contou com financiamento do FUNDESCOLA e, na sua expansão, com recursos do próprio estado, visando à "descentralização dos recursos". Inicialmente, em 1998, o PDE foi implantado em 67 escolas. Na fase de consolidação da ZAP I - 1998/1999, foram atendidas 30 escolas da rede estadual e 41 das redes municipais.

As escolas que iniciaram o PDE, em 1999, passaram por um processo de avaliação que resultou em uma classificação destas, definindo a continuidade ou não dos recursos. Em 1999, todas as 67 escolas que desenvolveram o PDE receberam $100 \%$ de recursos do FUNDESCOLA. Em 2000, apenas 42 escolas (as que foram classificadas) continuaram no processo e receberam novamente $100 \%$ de recursos 
do FUNDESCOlA. Em 2001, no entanto, as escolas não classificadas em 2000, e que não haviam recebido recursos, voltaram a recebê-los.

Os dados da Tabela 2 mostram o número de escolas financiadas, de 1998 a 2002, por ZAP I e II estadual e municipal. De um modo geral, os dados evidenciam aumento anual constante das escolas que se incorporaram ao programa e que receberam financiamento. ${ }^{12}$

\section{Tabela 2}

Número de escolas financiadas pelo FUNDESCOLA 1998 a 2002 - ZAP I

(estadual e municipal) e ZAP II (estadual e municipal)

\begin{tabular}{|l|c|c|c|c|}
\hline ESCOLAS & $1998-1999$ & $1999-2000$ & $2000-2001$ & $2001-2002$ \\
\hline Estaduais ZAP I & 27 & 96 & 202 & 202 \\
\hline Estaduais ZAP II & - & 30 & 87 & 95 \\
\hline Municipais ZAP I & 28 & 42 & 70 & 166 \\
\hline Municipais ZAP II & - & 41 & 31 & 123 \\
\hline
\end{tabular}

Fonte: SEE/COEP-GAE, 2002.

Os dados da ZAP I municipal registram que o aumento foi constante, especialmente em 2001/2002, quando se registrou mais de $100 \%$ de crescimento no número de escolas financiadas. De igual modo, quase todos os municípios também registraram crescimento de mais de $100 \%$. O crescimento do número de escolas financiadas, de 1998 a 2002, na ZAP II estadual e na ZAP II municipal, foi menor que na ZAP I estadual e na ZAP I municipal. Verifica-se que o crescimento de 1999/2000 para 2000/2001 foi bastante considerável, chegando a quase triplicar o número de escolas, ou seja, passou de 30 para 87 escolas financiadas. Na ZAP II municipal, ocorreu uma diminuição no número de escolas financiadas na passagem de 1999/2000 para 2000/2001, quando este passou de 41 para 31 escolas. No entanto, em 2001/ 2002, ocorreu um crescimento de mais de 300\%, fazendo com que o número de escolas chegasse a 123.

O número de alunos atendidos por ano com o financiamento PDE/FUNDESCOLA, de 1998 a 2002, na ZAP I estadual e na ZAP I municipal, também foi basicamente crescente, à exceção de 2001/2002 (Tabela 3). Isso se deve, provavelmente, à municipalização de algumas es- 
O programa Fundescola: concepções, objetivos, componentes e abrangência...

colas estaduais. Por sua vez, na ZAP I municipal, houve certa estagnação na passagem de 1999/2000 para 2000/2001 e, posteriormente, a retomada acentuada do crescimento. É necessário lembrar, ainda, que ocorreram processos de avaliação para classificação das escolas e que, sobretudo em 2000 e 2001, algumas não foram incluídas, ficando sem receber os recursos do FUNDESCOLA.

\section{Tabela 3}

Número de alunos atendidos pelo FUNDESCOLA 1998 a 2002 - ZAP I

(estadual e municipal) e ZAP II (estadual e municipal)

\begin{tabular}{|l|c|c|c|c|}
\hline ESCOLAS & $1998-1999$ & $1999-2000$ & $2000-2001$ & $2001-2002$ \\
\hline Estaduais ZAP I & 29.088 & 91.682 & 154.031 & 141.883 \\
\hline Estaduais ZAP II & - & 32.800 & 71.674 & 73.133 \\
\hline Municipais ZAP I & 13.631 & 32.156 & 33.745 & 92.062 \\
\hline Municipais ZAP II & - & 32.514 & 19.760 & 69.720 \\
\hline
\end{tabular}

Fonte: SEE/COEP-GAE, 2002.

O número de alunos atendidos por ano com o financiamento PDE/FUNDESCOLA, na ZAP II estadual, mais que dobrou entre os períodos $1999 / 2000$ e $2000 / 2001$. No entanto, permaneceu praticamente o mesmo em 2002. Já na ZAP II municipal, ocorreu uma considerável diminuição no número de alunos de $1999 / 2000$ para 2000/2001 e uma retomada considerável do crescimento de 2000/2001 para 2001/2002.

Em maio de 2002, o Estado de Goiás já havia assumido, com recursos próprios, 778 escolas, sendo que a rede estadual contava, na mesma data, com 1.247 escolas. Segundo informações da SEE, em maio de 2002, "todas as escolas do estado já tinham o PDE", embora algumas ainda não estivessem executando as propostas apresentadas.

É importante observar, ainda, que o financiamento assumido pelo FUNDESCOLA vem decaindo ano a ano, ao passo que o do estado vai aumentando progressivamente. Assim, verifica-se que os recursos do FUNDESCOLA, de responsabilidade do MEC (com empréstimo do BM), passam a ser assumidos paulatinamente pelo estado, o qual, ao final do projeto, incorpora plenamente a metodologia do PDE e o seu financiamento (Tabela 4). Para alguns gestores do sistema estadual, esse forma- 
to é positivo, pois contribui para que os estados e municípios assumam a descentralização da escola por meio do repasse de recursos direto para a escola. ${ }^{13}$ Assim, o PDE é visto como "um instrumento que vai forçar os governos a colocarem dinheiro direto na escola", mesmo com o fim do financiamento internacional, já que estão adotando inteiramente a metodologia do programa. A Tabela 4 mostra o financiamento das duas fontes.

\section{Tabela 4}

Porcentuais de financiamento assumidos pelo FUNDESCOLA e pelo Estado de Goiás, conforme o ano de implementação de programa

\begin{tabular}{|l|c|c|c|c|c|}
\hline Programa/Estado & $1^{\mathrm{o}}$ ano & $2^{\mathrm{o}}$ ano & $3^{\mathrm{o}}$ ano & $4^{\mathrm{o}}$ ano & $5^{\circ}$ ano \\
\hline Fundescola & $100 \%$ & $70 \%$ & $50 \%$ & $30 \%$ & $0 \%$ \\
\hline Estado & $0 \%$ & $30 \%$ & $50 \%$ & $70 \%$ & $100 \%$ \\
\hline
\end{tabular}

Fonte: SEE/COEP-GAE, 2002.

Goiás expandiu o PDE juntamente com outros estados da federação, entre os quais Acre, Mato Grosso, Rondônia e Tocantins. A explicação para isso se faz pelos "bons resultados apresentados pelas escolas que adotam o plano desde 1998" (FUNDESCOLA - Boletim Técnico, n. 56, 2002 , p. 3). Essa compreensão se faz baseada em avaliação do FUNDESCOLA I, realizada pelo BM, publicada em 2001, que dá conta de que "quase todas as metas previstas nos componentes foram alcançadas com êxito, superando largamente algumas delas", tais como taxas de matrícula, melhora nos padrões mínimos de funcionamento das escolas, certificação pelo Proformação, aquisição de mobiliário e equipamentos, além da implantação de um modelo de gestão em pelo menos metade dos municípios atendidos pelo programa (MEC/FUnDESCOLA, Boletim, n. 56, 2001, p. 6).

A expansão do PDE, em Goiás, levou a SEE a idealizar e implementar uma estratégia própria para universalização e acompanhamento do programa (Estado de Goiás/seE/CoEp, 2001, p. 2). Neste sentido, foi criada a figura de um supervisor/orientador, atualmente denominado professor/tutor, "para auxiliar no trabalho de assistência técnica e no acompanhamento do processo de elaboração e execução nas escolas" (idem, ibid., p. 3). Esse "professor supervisor/orientador" vai a cada es- 
O programa Fundescola: concepções, objetivos, componentes e abrangência...

cola, "uma vez por semana", para "ver a escola como um todo" e orientar, especialmente, o Comitê Estratégico, ou melhor, o Grupo de Sistematização, no que tange ao trabalho de realização do PDE. Esse trabalho é feito em cada etapa do programa. Ele é considerado "o agente multiplicador do PDE na escola" e, por essa razão, deve pertencer ao quadro efetivo da secretaria. O supervisor também tem a tarefa de orientar a escola com relação aos outros programas do FUNDESCOLA.

A "Proposta de Universalização do PDE" na rede estadual (Estado de Goiás/SEE/COEP, 2001) buscou atingir todas as escolas com mais de 100 alunos do ensino fundamental e ensino médio dos $242 \mathrm{mu}$ nicípios do estado. De acordo com a Tabela 5, a universalização do PDE alcança 205 municípios e 771 escolas. ${ }^{14}$

\section{Tabela 5}

Proposta de Universalização do PDE - 2001

\begin{tabular}{|c|c|c|c|c|c|c|}
\hline $\begin{array}{c}\mathrm{N}^{\circ} \text { de } \\
\text { municípios }\end{array}$ & $\begin{array}{c}\mathrm{N}^{\circ} \text { de } \\
\text { escolas }\end{array}$ & $\begin{array}{c}\text { No de } \\
\text { participantes da } \\
\text { escola } \\
\text { (capacitação das } \\
\text { equipes) }\end{array}$ & $\begin{array}{c}\mathrm{N}^{\circ} \text { total de } \\
\text { alunos das } \\
\text { escolas }\end{array}$ & $\begin{array}{c}\text { Valor } \\
\text { financiado R\$ }\end{array}$ & Capital & Custeio \\
\hline 205 & 771 & 3.855 & 351.409 & $5.835 .300,00$ & $2.334 .120,00$ & $3.501 .180,00$ \\
\hline
\end{tabular}

Fonte: Estado de Goiás, SEE/COEP, 2001.

Além disso, o governo estadual propôs e realizou a capacitação de 3.855 participantes no âmbito das escolas, sendo cinco de cada uma, considerados "liderança da escola" (diretor, coordenador pedagógico, secretário, um professor de forte liderança, um "pai” representante do Conselho Escolar). A proposta buscou capacitar a equipe central da SEE e equipes dos Departamentos Pedagógicos e Técnicos Operacionais das Subsecretarias e os subsecretários regionais. Ao todo, são 351.409 alunos atendidos por essas escolas. Segundo a Proposta, o valor financiado é de $\mathrm{R} \$ 5.835,300$, sendo $\mathrm{R} \$ 2.334,120$ para $c a-$ pital e R\$3.501,180 para custeio.

O FUNDESCOLA/PDE e sua materialização nas escolas de Goiás

De acordo com os dados da pesquisa, o PDE, principal estratégia do FUNDESCOLA, tem sido disseminado e acolhido por um número 
significativo de instituições escolares. A adesão das escolas ao programa explica-se pelo fato de que o desenvolvimento de um projeto de porte internacional significa prestígio para o quadro de direção que o acolhe, especialmente em virtude da destinação de recursos financeiros, os quais podem ser proporcionalmente elevados para o âmbito de um município e, principalmente, de uma escola. Além disso, o programa propõe-se a promover soluções em curto prazo para problemas institucionais crônicos, como evasão e repetência, deficiência numérica e má formação de docentes, além da falta de materiais, equipamentos e espaço físico adequados.

De acordo com a concepção inicial, a inclusão das escolas no FUNDESCOLA dar-se-ia por adesão. Na verdade, exige-se de cada instituição a apresentação de projetos que são julgados pela coordenação central do programa, segundo critérios definidos a priori, sem a participação das escolas. Portanto, a seleção induz a um sistema de competição, premiando as que se mostram mais preparadas para desenvolver os projetos.

Os resultados mostram que o PDE é avaliado de forma contraditória por parte dos gestores do sistema estadual. De um modo geral, os gestores avaliam positivamente o PDE, o que pode ser atestado por meio da adoção e universalização do projeto com recursos do próprio estado. Porém, alguns desses gestores informam que há, atualmente, certa convicção de que o modelo de gestão do $\mathrm{BM}$, por meio do PDE, é altamente diretivo e não leva à autonomia da escola, uma vez que, para sua execução, fixam-se exigências que o tornam altamente burocrático.

Por sua vez, o grupo de sistematização do projeto (diretor da escola, coordenador do PDE e coordenador de objetivos estratégicos) considera-o um instrumento primordial para facilitar a administração física da escola, uma vez que permite concretizar soluções imediatas, como reformas, compras de equipamentos e materiais. Neste sentido, não se pode negar que o PDE colabora com a autonomia financeira da escola, aspecto mais destacado pelos dirigentes escolares.

Os gestores, no nível da SEE, consideram o PDE um "instrumento para operacionalizar a Proposta Pedagógica da Escola”, já que "um puxa o outro". No entanto, acreditam que $50 \%$ das escolas não entendem essa relação entre o PDE e o Projeto Político-Pedagógico (PPP). Isso se deve, segundo depoimentos, ao fato de que boa parte das escolas não 
O programa Fundescola: concepções, objetivos, componentes e abrangência...

entendeu o que é o PPP e, por essa razão, não o implanta. Acreditam ainda que "com o PDE, mediante a participação, as escolas estão entendendo a necessidade de um projeto pedagógico". Portanto, "o PDE poderia levar ao PPP", uma vez que aquele "permite discutir os dados da escola, sua realidade". Há inclusive depoimento entusiasmado no sentido de que "o PDE é um instrumento para salvar a escola".

Os professores das escolas envolvidas, embora reconheçam que existem benefícios para a escola, do ponto de vista físico e material, não consideram o PDE um promotor de mudanças mais qualitativas no âmbito pedagógico. Além disso, afirmam que as exigências burocráticas aumentam a carga de atividades processuais, sem que contribuam necessariamente para o trabalho em sala de aula.

$\mathrm{Na}$ verdade, de acordo com os resultados da presente investigação, a autonomia da gestão fundamenta-se na liderança do diretor, a partir da adoção de medidas de treinamento intensivo em planejamento estratégico, abordando assuntos tais como mobilização da comunidade, gestão de recursos e planejamento da carreira do professor. O importante é buscar meios de financiar melhorias de qualidade e expansão de acesso, sem onerar a carga fiscal do investimento em educação, considerada bastante alta para o país. Portanto, apela-se para alternativas de financiamento e de estratégias que atinjam o sistema, sem aumentar os custos.

Assim, o PDE expressa uma modalidade de reforma voltada para a estrutura do sistema educativo tendo, como alvo principal, a racionalização de gastos e a eficiência operacional, sendo a questão pedagógica tratada secundariamente, como decorrência automática dos procedimentos que afetam o funcionamento escolar.

Embora, em sua concepção inicial, o FUNDESCOLA enfatize a possibilidade de aumento do poder de decisão para as escolas, na prática a própria sistemática de co-financiamento internacional impõe instrumentos de controle sobre os projetos, como manuais para acompanhamento e planejamento de ações, além de normas para utilização de recursos e prestação de contas do dinheiro repassado à escola, para aquisição de materiais e melhoria do espaço escolar. Se, de um lado, esses instrumentos ajudam a organizar o trabalho rotineiro da escola, de outro, dificultam ou até mesmo impedem as decisões autônomas sobre outras questôes mais pedagógicas, como a realização de cursos 
de formação docente e a adequação das condições de trabalho em sala de aula.

No tocante ao trabalho escolar, imprime-se uma organização que se aproxima da racionalidade taylorista, na medida em que recupera princípios e métodos da gerência técnico-científica: facilita a divisão pormenorizada do trabalho escolar, com nítida separação entre quem decide e quem executa as ações; diluem-se as atividades escolares, muitas entre elas preexistentes ao $\mathrm{PDE}$, em inúmeros projetos desarticulados e com "gerências" próprias.

De par com a fragmentação do trabalho, ocorre a "diluição de poderes" entre os membros da mesma coletividade, onde cada um é responsável apenas por uma parte do poder decisório. A concepção teórica já vem definida por "instâncias superiores”, como costumam referir-se os membros da escola.

Fica evidente que, dentro da mesma esfera governamental, convivem duas concepções antagônicas de gestão educacional, provenientes de diferentes matrizes teóricas. Uma de caráter burocrático, que internaliza modelos concebidos por agências financeiras internacionais e outra que sinaliza a aspiração da comunidade educativa por uma escola mais autônoma e de qualidade e que conhecemos como "Projeto Político-Pedagógico". A proposta foi incluída na Lei de Diretrizes e Bases da Educação Nacional de 1996, no inciso I do artigo 13. O Plano Nacional de Educação (Brasil, 2001) também afirma a necessidade de uma proposta escolar autônoma, ressaltando a importância da participação dos profissionais da educação e da comunidade escolar em conselhos escolares ou equivalentes, para estimular a autonomia da escola.

Além disso, há que considerar que o PPP tem sido tema de propostas inovadoras, concebidas no espaço acadêmico, buscando superar a gestão dos meios e produtos, orientando-se por valores que levem em conta as vivências e as condições de vida e de trabalho, a cultura escolar e a qualificação dos professores. Incentiva ainda novos aportes em seu processo de formação que possibilitem maior criatividade na sua prática de sala de aula e que promovam a satisfação das expectativas cognitivas e afetivas dos alunos. Valoriza, também, mais o saber construído pela própria escola que a capacidade de especialistas que lhe são exteriores. 
O programa Fundescola: concepções, objetivos, componentes e abrangência...

No entanto, é a proposta burocrática que se fortalece institucionalmente. Por meio do PDE, as escolas concretizam um projeto de modernização, diretividade e controle da gestão e do trabalho escolares, impulsionadas pelo próprio prestígio dos acordos internacionais, com sua aura de modernização gerencial e aporte de recursos financeiros. Dessa forma, o PDE sobrepóe-se ao PPP, instituindo uma forma de gestão que fragmenta as ações escolares, sem uma direção política que as aglutine em proposta educacional mais articulada e com sentido político.

Os gestores acreditam, no entanto, que estão dando uma direção ao trabalho escolar, por meio de uma metodologia quase infalivel que, se seguida à risca, ${ }^{15}$ leva à participação coletiva em prol da melhoria da qualidade de ensino e do desempenho da escola. No entanto, essa racionalidade imposta à gestão não leva em conta o modo de ser e o de agir que dão substância à cultura escolar, pois esta não é percebida como uma instituição complexa, cuja organização, gestão e produção do trabalho exigem iniciativas que ultrapassam os limites impostos pela racionalidade presente no modelo de planejamento estratégico.

Tendo por base os dados do processo de implementação, expansão e universalização do PDE em Goiás, é possível afirmar que, na prática, produz-se um processo de subsunção formal e real da organização e da gestão do trabalho escolares aos objetivos, às técnicas e às rotinas de trabalho estabelecidos pelos modelos de planejamento e gerenciamento estratégico, definidos no PDE. Essa percepção foi corroborada em depoimentos de gestores do sistema estadual, quando informam que há, atualmente, certa convicção de que o modelo de gestão do BM, executado por meio do PDE, é altamente diretivo e não leva à autonomia da escola, conforme foi estabelecido em sua proposta inicial. Os gestores municipais também realçaram esse caráter diretivo do projeto, pois as escolas são escolhidas à revelia das secretarias, o que não coaduna com uma perspectiva de gestão democrática e de implementação de um projeto político-pedagógico, produzido coletivamente no interior de cada escola.

De um modo geral, o sistema gerencial estabelecido nas escolas, por meio do PDE, cumpre o velho propósito da administração científica, qual seja: controlar, já que a gerência sem controle não é concebível. Como afirma Braverman (1987, p. 113): 
(...) o conceito de controle adotado pela gerência moderna exige que cada atividade na produção tenha suas diversas atividades paralelas no centro gerencial: cada uma delas deve ser prevista, pré-calculada, experimentada, comunicada, atribuída, ordenada, conferida, inspecionada e registrada através de toda a sua duração e após conclusão. O resultado é que o processo de produção é reproduzido em papel antes e depois que adquire forma concreta.

Além disso, a organização e a divisão pormenorizada do trabalho, o controle das decisões, o parcelamento das atividades e das atribuiçôes, a vigilância contínua em todas as fases do trabalho e a intensificação do trabalho, visando ao maior controle e, conseqüentemente, à maior eficiência, são claramente percebidos no modelo gerencial implementado pelo PDE.

Resta indagar, portanto: por que o Estado de Goiás e outros estados da federação optaram pela universalização do PDE, como instrumento de planejamento estratégico, resultante de uma concepção compartilhada entre o BM e o MEC, quando poderiam ter dado continuidade ao processo de implementação do projeto político-pedagógico da escola, inclusive como uma das exigências da LDB, no que tange à consecução da gestão democrática?

Recebido em março de 2004 e aprovado em dezembro de 2005.

\section{Notas}

1. Cabe aqui um esclarecimento sobre a denominação do Banco Mundial (BM). Embora diferentes siglas sejam utilizadas como sinônimos, о BM compreende um grupo de instituições financeiras, entre elas, o Banco Internacional para Reconstrução e Desenvolvimento (BIRD), que constitui o financiador de projetos para diferentes setores econômicos e sociais, sendo, portanto, a agência de crédito que empresta para a educação brasileira. No contexto desta pesquisa, a título de simplificação, utilizaremos a denominação Banco Mundial ou BM, como é mais conhecido.

2. No fundescola I (1997-2002), em Goiás, só foram implantados dois projetos: o PDE e a Escola Ativa.

3. Zona(s) de Atendimento Prioritário.

4. No caso do FUNDESCOLA, documento elaborado pelo Banco para a primeira fase do acordo denomina-se: The World Bank. Project Appraisal Repport on a proposed loan in the amount of US\$ 62.5 million to the Federal Republic of Brazil for the School Improvement Project - FUndescola I. Washington: The World Bank, 1998. Na segunda fase do acordo, o montante chega a US\$202,03 milhões.

Educ. Soc., Campinas, vol. 26, n. 90, p. 127-147, Jan./Abr. 2005

Disponível em <http://www.cedes.unicamp.br> 
O programa Fundescola: concepções, objetivos, componentes e abrangência...

5. Cf. "Manual de operação e implementação do Projeto Fundescola IIIA" (Brasil/MeC/ FUNDESCOLA, 2002).

6. O FUNDESCOLA III foi assinado durante a realização da presente pesquisa, encontrando-se em fase de implementação.

7. Em documentos do BM, ensino primário refere-se às quatro séries iniciais do ensino fundamental, o que corresponde aos alunos na faixa etária de 7 a 10 anos. No Brasil, o ensino fundamental é composto de oito séries obrigatórias, sem divisão entre elas.

8. Os documentos oficiais referem-se aos projetos que compõem o FUNDESCOLA como "Produtos".

9. O prasem como também o Escola Ativa são ações iniciadas no Projeto Nordeste, que antecedeu o FUNDESCOLA; eles foram ampliados e estão sendo consolidados durante o FUNDESCOLA (FUNDESCOLA - Boletim Técnico, n. 56, 2002). Há ainda os encontros da Justiça com a Educação - FICAE - um protocolo de ajuste de conduta. Com relação à construção escolar, em Goiás, que fica dentro do microplanejamento do estado, estão dez escolas de assentamento e seis escolas urbanas, nas seguintes cidades: Aparecida de Goiânia, Senador Canedo, Teresópolis, Novo Gama, Águas Lindas, Planaltina e Goianápolis.

10. As escolas em convênio com o FUNDESCOLA classificam-se em: Implantação, Expansão e Consolidação I, II e III.

11. A escolha dessas escolas levou em conta o IDH. O IDH mede os progressos efetuados em cada país em termos de parâmetros sociais e econômicos fundamentais. Em setembro de 2003 saiu índice novo e Goiás aparece com IDH de 0,776, maior que a média nacional, que é de 0,769 . O DF tem IDH de 0,844 . O IDH utiliza como critério a educação (alfabetização e taxa de matrícula), longevidade e renda per capita. Disponível em: <www.rankbrail.com.br/ geopolitica/idh_brasil.htm>.

12. O PDE de uma escola é aprovado em um ano e iniciado no ano seguinte.

13. O governo federal, por intermédio do Programa Dinheiro Direto na Escola (PDDE), repassa recursos diretamente para as escolas, o que é acompanhado, na rede estadual, pelo PróEscola, isto é, pela cota estadual do FNDE/FUNDEF. Neste sentido, a SEE incentivou as escolas a terem sua unidade executora, ou seja, o seu "caixa escolar" para viabilizar o planejamento e a execução dos recursos recebidos. Segundo depoimentos, a SEE e grande parte das SME não aceitaram colocar os recursos do PDDE no PDE, o que permitiu às escolas maior flexibilidade na utilização desses recursos. Entretanto, a partir de 2002, no processo de universalização, tornou-se prática, nas escolas estaduais, a programação de todos os recursos (PDDE e PróEscola) no PDE.

14. Observa-se que a Proposta de Universalização não contempla todos os municípios do estado, embora seja um dos objetivos gerais declarados no documento.

15. Nas orientações para a Gerência de Apoio à Escola (GAE) e para a equipe técnica responsável pelo PDE, consta que "nenhum técnico da GAE e do GDE está autorizado a permitir qualquer mudança na metodologia contida no Manual” (Estado de Goiás/SEE/GAE, 2002).

\section{Referências bibliográficas}

\section{AMARAL SOBRINHO, J. O PDE e a gestão escolar no Brasil. Brasília, DF: MEC/BIRD/FUNDESCOLA, 2001.}


BRASIL. Ministério da Educação. Fundescola: Boletim Técnico, Brasília, DF, v.7, n. 56, 2002.

BRASIL. Ministério da Educação. Fundescola: Manual de operação e implementação do Projeto FUNDESCOLA IIIA (MOIP). Brasília, DF: MEC, 2002.

BRASIL. Ministério da Educação. Fundescola: O programa. Disponível em: <www.fundescola.org.br>. Acesso em: mar. 2002.

BRASIL. Ministério da Educação. Fundescola: Fundo de fortalecimento da escola: 1998-2002. Brasília, DF: MEC, 2003.

GOIÁS (Estado). Secretaria Estadual de Educação. Gerência de Apoio à Escola (GAE). Goiânia, 2002.

GOIÁS (Estado). Secretaria Estadual de Educação. Coordenação Estadual Executiva do Projeto (coep/go - Fundescola). Proposta de universalização do PDE. Goiânia: SEE/COEP/GO - FUndescola, 2001.

GOIÁS (Estado). Secretaria Estadual de Educação. Coordenação Estadual Executiva do Projeto (coep/Go - Fundescola). Tabela de Financiamento: FUNDESCOLA 1998-2002, ZAP I, Estadual. Goiânia: SEE/COEP/ GO - FUNDESCOLA, 2001.

KRUPPA, S. O Banco Mundial e as políticas públicas de educação nos anos 90. 2001. Tese (Doutorado) - Faculdade de Educação, Universidade de São Paulo, São Paulo.

LIMA, L.C. A escola como organização educativa: uma abordagem sociológica. São Paulo: Cortez, 2001.

MARRA, F.; BOF, A.; AMARAL SOBRINHO, J. Plano de desenvolvimento da escola: conceito, estrutura e prática. Brasília, DF: MEC/BIRD/ FUNDESCOLA, 1999.

WORLD BANK. Project Appraisal Repport on a proposed loan in the amount of US\$ 62.5 million to the Federal Republic of Brasil for the School Improvement Project: FUndescola I. Washington, DC, 1998.

WORLD BANK. Documento de avaliação de projeto sobre um empréstimo proposto no valor equivalente a US\$202,03 milhöes para a República Federativa do Brasil para o Segundo Projeto de Fortalecimento da Escola: FUndescola II. Washington, DC, 1999. 